\title{
Metal loading effect on rare earth element binding to humic acid:
}

\section{experimental and modelling evidence}

Rémi Marsac*, Mélanie Davranche, Gérard Gruau and Aline Dia

Géosciences Rennes, UMR CNRS - Université Rennes 1 N$^{\circ} 6118$, Campus de Beaulieu, 35042 Rennes Cedex, France

*Corresponding author: Tel +33223236 083; Fax: +33223236090

E-mail address: remi.marsac@univ-rennes1.fr 
1 Abstract- The effect of metal loading on the binding of rare earth elements (REE) to humic 2 acid (HA) was studied by combining ultrafiltration and Inductively Coupled Plasma Mass 3 Spectrometry techniques. REE-HA complexation experiments were performed at $\mathrm{pH} 3$ for $4 \mathrm{REE} / \mathrm{C}$ molar ratios ranging from ca $4 \cdot 10^{-4}$ to $2.7 .10^{-2}$. Results show that the relative amount 5 of REE bound to HA strongly increases with decreasing REE/C. A middle-REE (MREE) 6 downward concavity is shown by $\log \mathrm{K}_{\mathrm{d}}^{\mathrm{REE}}$ patterns at high metal loading, whereas patterns at 7 low metal loading display a regular increase from La to Lu. Humic Ion Model VI modelling 8 are close to the experimental data variations, provided that (i) the $\Delta \mathrm{LK}_{2}$ parameter (i.e. the 9 Model VI parameter taken into account the presence of strong but low density binding sites) is allowed to increase regularly from $\mathrm{La}$ to $\mathrm{Lu}$ (from 1.1 to 2.1 ) and (ii) the published $\log \mathrm{K}_{\mathrm{MA}}$ 11 values (i.e. the REE-HA binding constants specific to Model VI) are slightly modified, in particular with respect to heavy REE. Modelling approach provided evidence that $\log \mathrm{K}_{\mathrm{d}}^{\mathrm{REE}}$ patterns with varying REE/C likely arises because REE binding to HA occurs through two types of binding sites in different density: (i) a few strong sites that preferentially complex the heavy REE and thus control the $\log \mathrm{K}_{\mathrm{d}}^{\mathrm{REE}}$ patterns at low $\mathrm{REE} / \mathrm{C}$; (ii) a larger amount of weaker binding sites that preferentially complex the middle REE and thus control the $17 \log \mathrm{K}_{\mathrm{d}}^{\mathrm{REE}}$ pattern at high REE/C. Hence, metal loading exerts a major effect on HA-mediated REE binding, which could explain the diversity of published conditional constants for REE 19 binding with HA. A literature survey suggests that the few strong sites activated at low $20 \mathrm{REE} / \mathrm{C}$ could be multidentate carboxylic sites, or perhaps N-, or P-functional groups. Finally, 21 an examination of the literature field data proposed that the described loading effect could account for much of the variation in REE patterns observed in natural organic-rich waters (DOC $>5 \mathrm{mg} \mathrm{L}^{-1}$ and $\left.4 \leq \mathrm{pH} \leq 7\right)$. 
1 Keywords: rare earth elements, humic acid, complexation constant, metal loading, modelling,

2 WHAM 6/Model VI.

\section{INTRODUCTION}

There is now widespread evidence that rare earth elements (REE) in natural organic waters occur as organic complexes (Bidoglio et al., 1991; Glaus et al., 1995; Takahashi et al., 1997; Viers et al., 1997; Dia et al., 2000; Tang and Johannesson, 2003; Gruau et al., 2004; Pourret et al., 2007a, b; Glaus et al., 2000; Yamamoto et al., 2005; Sonke and Salters, 2006; Stern et al., 2007; Pédrot et al., 2008; Yamamoto et al., 2009b). This explains why the determination of conditional binding constants of the REE by humic acids (HA) has recently become a major issue of REE hydrochemical studies (Tang and Johannesson, 2003; Yamamoto et al., 2005; Sonke and Salters, 2006; Pourret et al., 2007a, b; Stern et al., 2007; and Yamamoto et al., 2009b). Several recent studies showed that determining such constants is not an easy task because of the presence of a possible metal loading effect, leading to variations in the $\log \mathrm{K}_{\mathrm{d}}^{\mathrm{REE}}$ patterns with variations in REE/HA ratio. Thus, Yamamoto et al. (2005 and 2006) and Pourret et al. (2007b) reported a middle REE (MREE) downward concavity in the $\log \mathrm{K}_{\mathrm{d}}^{\mathrm{REE}}$ patterns from complexation experiments conducted at high metal loading (i.e. REE/C molar ratio ranging from $10^{-3}$ to $1.5 .10^{-2}$, with $\mathrm{C}$ corresponding to the amount of organic carbon). By contrast, Sonke and Salters (2006) and Stern et al. (2007) reported an overall increase of the $\log \mathrm{K}_{\mathrm{d}}^{\mathrm{REE}}$ values from $\mathrm{La}$ to $\mathrm{Lu}$ (so-called lanthanide contraction effect) from experiments at much lower REE/C $\left(10^{-4}\right)$. One possible explanation for this discrepancy is that the binding of the REE with HA occurs through the heterogeneity of the HA binding sites, having different stability constants and occurring in markedly distinct density. More specifically, the "lanthanide contraction effect" observed in low metal loading experiments could be due to the dominant binding of the REE to high affinity sites which, 
1 although occurring in the range of a few percent, would determine the $\log \mathrm{K}_{\mathrm{d}}^{\mathrm{REE}}$ pattern under

2 such low REE/C conditions. These sites, whose binding strength regularly increases with the

3 REE atomic number, could be multidendate carboxylic sites, or phenolic, or aminocarboxylic

4 sites as suggested by Stern et al. (2007) and Pourret and Martinez (2009). Alternatively, the MREE downward concavity observed at high metal loading could be due to the binding characteristics of high density but weak sites, which would determine the HA binding under high REE/C conditions. These sites would complex the MREE much more efficiently than the LREE and the HREE, and could be attributed to carboxylic sites, which are known to be the main binding sites of REE in HA as demonstrated by NEXAFS analysis (C 1s-near edge $\mathrm{X}$ ray absorption fine structure) of Eu-HA complexes at high $\mathrm{Eu} / \mathrm{C}$ ratio (Plaschke et al., 2004). The binding characteristics of different trace metals with HA were previously studied by adsorption isotherm experiments. These studies focused on the binding of $\mathrm{Al}$ (Kinniburg et al. 1999), Ca, Cd, Cu (Benedetti et al. 1995), Am (Peters et al., 2001), As (Buschmann et al., 2004), Sb (Buschmann and Sigg, 2006), Pb and Cd (Abate and Masini, 2002) to humic substances (HS), evidenced an increase in the binding strength following the metal loading decrease, that can be related to HS surface site heterogeneity. Such non-linear binding was also observed by Hummel et al. (2000) for Eu complexation to HA. These studies agree with the hypothesis of a variation of the apparent $\log \mathrm{K}_{d}^{\mathrm{REE}}$ patterns with $\mathrm{REE} / \mathrm{C}$ due to the heterogeneity of the HA binding sites occurring at different density. More recently, Yamamoto et al. (2009b) demonstrated a regular and progressive evolution of the $\log \mathrm{K}_{\mathrm{d}}^{\mathrm{REE}}$ patterns with decreasing metal loading, from a downward concave MREE distribution to a pattern showing the lanthanide contraction effect. However, this hypothesis still lacks corroboration from a comprehensive study involving experimental and modelling approaches. In the present study, REE-HA binding experiments were performed simultaneously on the 14 naturally occurring REE over a wide range of REE/C molar ratio (ranging from $4.10^{-4}$ 
1 to $2.7 \cdot 10^{-2}$ ). Whereas the Sonke and Salters study used CE-ICPMS at low REE/C and the

2 Pourret et al. (2007) study used ultrafiltration combined with ICP-MS, at high metal loading,

3 all the here below presented data were obtained using same combined ultrafiltration and ICP-

4 MS techniques. The experimental data are analysed to assess the variation in binding sites

5 with changing REE/C using Humic Ion binding Model VI (hereafter denoted as Model VI),

6 developed by Tipping (1998). Finally, a compilation of 350 samples of organic-rich, river-,

7 and soil-waters were pooling to show whether variations in REE pattern displayed by natural

8 organic-rich waters could be due to a metal loading effect.

\section{MATERIALS AND METHODS}

All chemicals used in this study were of analytical grade, with all experimental 11 solutions being prepared with doubly-deionised water (Milli-Q system, Millipore ${ }^{\mathrm{TM}}$ ). 12 Synthetic REE solutions were prepared from a nitrate REE standard $\left(10 \mathrm{mg} \mathrm{L}^{-1}\right.$, Accu Trace ${ }^{\mathrm{TM}}$ 13 Reference Standard). Polyethylene containers used to attain REE-HA complexation equilibrium were all previously soaked in $10 \%$ Ultrapure $\mathrm{HNO}_{3}$ for $48 \mathrm{~h}$ at $60^{\circ} \mathrm{C}$, then rinsed with deionised water for $24 \mathrm{~h}$ at $60^{\circ} \mathrm{C}$ to remove all REE contamination sources. All experiments were performed at room temperature, i.e. $20^{\circ} \mathrm{C} \pm 2$.

\subsection{Humic acid}

Purified humic acid (HA) was obtained from synthetic Aldrich humic acid (Aldrich ${ }^{\mathrm{TM}}$, H1, 675-2). The purification was performed with the protocol of Vermeer et al. (1998), except that a tangential ultrafiltration step was added to remove any possible HA molecules $<10 \mathrm{kDa}$ using a Labscale TFF system equipped with a Pellicon XL membrane (PLCGC10, Millipore $\left.^{\mathrm{TM}}\right)$. Humic acid was freeze-dried and stored in a glass container. Prior to use, purified HA was solubilized overnight in a solution of $0.01 \mathrm{M} \mathrm{NaCl}$ at $\mathrm{pH}=10$ to ensure complete dissolution (Vermeer et al., 1998). 


\subsection{Experimental set-up of the REE binding with HA}

3 HA. The fourteen REE were added simultaneously to a solution of 5 to $40 \mathrm{mg} \mathrm{L}^{-1}$ of $\mathrm{HA}$ and

$410^{-2} \mathrm{M} \mathrm{NaCl}$. The REE/C (metal loading) varied from $4 \cdot 10^{-4}$ to $2 \cdot 7 \cdot 10^{-2}$. REE-HA binding experiments were carried out at $\mathrm{pH}=3$. This acidic $\mathrm{pH}$ was chosen to avoid total complexation of the REE with HA, and to prevent complexation of the REE inorganic fraction by $\mathrm{OH}^{-}$and $\mathrm{CO}_{3}{ }^{2-}$. Regards to their low stability constants $(-0.66<\log \beta<-0.41$ at 0.7 $\mathrm{M}$ ionic strength and $25^{\circ} \mathrm{C}$ ) (Byrne and Sholkovitz, 1996), REE-Cl complexes were neglected. All inorganic REE can thus be confidently assumed to occur as free aqueous $\mathrm{REE}^{3+}$ species in all the experiments, and are modelled accordingly (Tang and Johannesson, 2003; Pourret et al., 2007a). According to Yamamoto et al., (2009a,b), Al and Fe form stable complexes with carboxylic sites within humic substances and cannot be excluded completely by purification of HA. Although humic acid was here purified with an acidic cation-exchange resin (Dionex 50) at $\mathrm{pH} 1$, part of $\mathrm{Al}$ and Fe could effectively remain onto HA. Therefore, HA sites strongly bound with residual $\mathrm{Fe}$ and $\mathrm{Al}$ may be considered as not available for cation binding. Moreover, HA site density is generally evaluated by potentiometric titration carried out between pH 2 and 11 (e.g. Ritchie and Perdue, 2003). Considering the titration pH, titrations do not allow to remove this residual $\mathrm{Fe}$ and $\mathrm{Al}$ from HA surface. In consequence, the HA sites strongly bound with Fe and Al do not account for surface site density. Therefore, the potential effect of residual $\mathrm{Al}$ and $\mathrm{Fe}$ on $\mathrm{REE}$ binding was not taken into account in this study. Prior to REE addition, the $\mathrm{pH}$ was adjusted directly to a value of 3 in the HA suspensions, which were then filtered to remove any potential precipitate. The dissolved organic carbon (DOC) concentration was then measured to assess the true HA concentration of the filtrate. Immediately following REE addition, a solution aliquot was systematically 
1 analysed to determine the exact REE concentration and thus the true REE/C of each 2 experimental suspension.

Experimental suspensions were stirred for $48 \mathrm{~h}$ to reach equilibrium according to the

4 protocol defined by Pourret et al. (2007b). The pH was monitored regularly with a combined

5 Radiometer Red Rod electrode, calibrated with WTW standard solutions ( $\mathrm{pH} 4$ and 7). The

6 accuracy of $\mathrm{pH}$ measurements was $\pm 0.05 \mathrm{pH}$ units. At equilibrium $(48 \mathrm{~h}), 10 \mathrm{~mL}$ of the

7 suspension were sampled and ultra-filtered at $5 \mathrm{kDa}$ to separate the REE-HA complexes from

8 the remaining inorganic REE. Ultrafiltrations were carried out by centrifuging the suspension

9 aliquots through $15 \mathrm{~mL}$ centrifugal tubes equipped with permeable membranes of $5 \mathrm{kDa}$ pore

10 size (Vivaspin 15RH12, Sartorius). All the membranes used were first washed with 0.15 mol

$11 \mathrm{~L}^{-1} \mathrm{HCl}$, then rinsed twice with MilliQ water to minimise contamination. Centrifugations were performed using a Jouan G4.12 centrifuge with swinging bucket rotor at $3000 \mathrm{~g}$ for $30 \mathrm{~min}$.

Dissolved organic carbon concentrations measured in the ultrafiltrates were systematically lower than or equal to $0.1 \mathrm{mg} \mathrm{L}^{-1}$, a concentration corresponding to the blank value currently observed in our laboratory (e.g. Pourret et al., 2007b). The $10 \mathrm{kDa}$ ultrafiltration step added in the HA purification protocol ensures that no organic molecules pass through the $5 \mathrm{kDa}$ ultrafiltration cells. Previously, Pourret et al. (2007b) showed from mass balance calculations, that more than $98 \%$ of REE were recovered and that REE 19 adsorption onto the membrane and the cell device was insignificant. Hence, the 20 concentrations of REE complexed to HA correspond strictly to the difference between the 21 initial REE concentration and the REE concentration in the $<5 \mathrm{kDa}$ ultrafiltrate. $\mathrm{K}_{\mathrm{d}}$, as follows:

$$
\mathrm{K}_{\mathrm{d}}\left(\operatorname{Ln}_{\mathrm{i}}\right)=\frac{\mu \mathrm{gLn} \mathrm{i}_{\mathrm{i}} \text { adsorbed } \mathrm{L}^{-1} / \mathrm{g} \text { DOC }}{\mu \mathrm{gLn}_{\mathrm{i}}{ }^{3+} \mathrm{mL}^{-1}}
$$


$1 \quad$ where $\mathrm{Ln}_{\mathrm{i}}=\mathrm{La}$ to $\mathrm{Lu}$.

\subsection{Solution analysis}

Rare earth element concentrations were determined at Rennes I University with an Agilent Technologies ${ }^{\mathrm{TM}}$ HP4500 ICP-MS instrument. All sample solutions were injected directly, except the initial suspensions, which were analysed to determine precisely the $\mathrm{REE} / \mathrm{C}$ ratios for each experiment. The suspensions were first digested with sub-boiled nitric acid $\left(\mathrm{HNO}_{3} 14 \mathrm{~N}\right)$ at $100^{\circ} \mathrm{C}$, then resolubilized in $\mathrm{HNO}_{3} 0.37 \mathrm{~N}$ after complete evaporation to avoid interferences with organic matter during mass analysis by ICP-MS. Quantitative analyses were performed using a conventional external calibration procedure. Three external standard solutions with REE concentrations similar to the analysed samples were prepared from a multi-REE standard solution (Accu Trace ${ }^{\mathrm{TM}}$ Reference, $10 \mathrm{mg} \mathrm{L}^{-1}$, USA). Indium was added to all samples as an internal standard at a concentration of $0.87 \mu \mathrm{mol} \mathrm{L} \mathrm{L}^{-1}(100 \mathrm{ppb})$ to correct for instrumental drift and possible matrix effects. Indium was also added to the external standard solutions. Calibration curves were calculated from measured REE/indium intensity ratios. As established from repeated analyses of multi-REE standard solution (Accu Trace $^{\mathrm{TM}}$ Reference, USA) and the SLRS-4 water standard, the instrumental error on REE analysis is below $3 \%$. Chemical blanks of all individual REE were all lower than detection $\operatorname{limit}\left(\operatorname{lng} \mathrm{L}^{-1}\right)$, and are thus negligible.

Dissolved organic carbon concentrations were determined using a Shimadzu 5000 TOC analyzer. The accuracy of DOC concentration measurements is estimated at $\pm 5 \%$, as determined by repeated analysis of freshly prepared standard solutions (potassium biphtalate).

\subsection{Humic Ion binding Model VI}

The Humic Ion binding Model VI (Model VI) has been precisely described by Tipping (1998). This model is a discrete binding site model which takes into account electrostatic 
1 interactions. Eight sites are considered, divided into an equal number of Type A sites (the

2 weak acidic group, commonly associated with carboxylic functional groups) and Type B sites

3 (the strong acidic group, commonly associated with phenolic functional groups). There are $\mathrm{n}_{\mathrm{A}}$

$4 \quad\left(\mathrm{~mol} \mathrm{~g}^{-1}\right)$ Type A sites and $\mathrm{n}_{\mathrm{A}} / 2\left(\mathrm{~mol} \mathrm{~g}^{-1}\right)$ Type B sites. The thermodynamic properties of each

5 site are described by intrinsic proton-binding constants $\left(\mathrm{pK}_{\mathrm{A}}\right.$ or $\left.\mathrm{pK} \mathrm{B}_{\mathrm{B}}\right)$ and the spread of the

6 values $\left(\Delta \mathrm{pK} \mathrm{A}_{\mathrm{A}}\right.$ or $\left.\Delta \mathrm{pK} \mathrm{K}_{\mathrm{B}}\right)$. Cation binding is described by the intrinsic binding constant of a

7 given cation with each type of site (namely, $\log \mathrm{K}_{\mathrm{MA}}$ and $\log \mathrm{K}_{\mathrm{MB}}$ ), together with a parameter

$8\left(\Delta \mathrm{LK}_{1}\right)$ describing the spread of values around the median. By considering results from many

9 datasets, a universal average value of $\Delta \mathrm{LK}_{1}$ was obtained for all cations, and a correlation

10 established between $\log \mathrm{K}_{\mathrm{MB}}$ and $\log \mathrm{K}_{\mathrm{MA}}$ (Tipping, 1998). Model VI parameters used for

11 REE binding to humic acid modelling (Tipping, 1998) are presented in Table 1.

Model VI also takes into account the formation of bidentate and tridentate complexes

24 (All experimental data can be found in the supplementary file)

\section{RESULTS}




\subsection{Experimental data}

The influence of metal loading on REE complexation with HA is examined by

4 considering the variation of the REE distribution coefficient $\left(\log \mathrm{K}_{\mathrm{d}}^{\mathrm{REE}}\right)$ patterns as a function

5 of the REE/C (Fig. 1). Firstly, a variation in the $\log \mathrm{K}_{\mathrm{d}}^{\mathrm{REE}}$ value is observed from 4.8 to 6.6

6 for $\mathrm{La}$, and from 4.8 to 7.3 for Lu over the range of tested REE/C (from $4.10^{-4}$ to $2.7 .10^{-2}$ ).

7 Secondly, and more importantly, the suggested variation of the $\log \mathrm{K}_{\mathrm{d}}^{\mathrm{REE}}$ patterns with

8 changing REE/C is confirmed (see discussions in Pourret et al., 2007b and Stern at al., 2007).

9 More specifically, $\log \mathrm{K}_{\mathrm{d}}^{\mathrm{REE}}$ patterns at low REE/C display a continuous enrichment from La

10 to $\mathrm{Lu}$, a feature already reported by Sonke and Salters (2006) and Stern et al. (2007) for

11 patterns obtained at similarly low REE/C. Conversely, $\log \mathrm{K}_{\mathrm{d}}^{\mathrm{REE}}$ patterns at high REE/C show

12 the typical downward concavity of the MREE earlier reported by Davranche et al. (2005),

13 Yamamoto et al., (2005) and Pourret et al., (2007b) from high metal loading experiments.

14 This $\log \mathrm{K}_{\mathrm{d}}^{\mathrm{REE}}$ pattern variation can be quantified by means of the $\log \left(\mathrm{K}_{\mathrm{d}}^{\mathrm{La}} / \mathrm{K}_{\mathrm{d}}^{\mathrm{Sm}}\right)$ and $15 \log \left(\mathrm{K}_{\mathrm{d}}^{\mathrm{Gd}} / \mathrm{K}_{\mathrm{d}}^{\mathrm{Yb}}\right)$ (denoted below as $\log (\mathrm{La} / \mathrm{Sm})$ and $\log (\mathrm{Gd} / \mathrm{Yb})$, respectively). Indeed, the $16 \log \mathrm{K}_{\mathrm{d}}^{\mathrm{REE}}$ patterns from low REE/C experiments - displaying the typical increase from La to $\mathrm{Lu}$ - are characterized by $\log (\mathrm{La} / \mathrm{Sm})$ and $\log (\mathrm{Gd} / \mathrm{Yb})$ values $<0$, whereas patterns from high

REE/C experiments - showing the characteristic downward concavity of the MREE - have log $(\mathrm{La} / \mathrm{Sm})$ and $\log (\mathrm{Gd} / \mathrm{Yb})$ ratios $<0$ and $>0$, respectively. As a whole, the $\log (\mathrm{Gd} / \mathrm{Yb})$ decreases more strongly with decreasing $\mathrm{REE} / \mathrm{C}$ (from 0.11 for $\mathrm{REE} / \mathrm{C}=2.7 .10^{-2}$ to -0.35 for $\left.\mathrm{REE} / \mathrm{C}=4.10^{-4}\right)$ than the $\log (\mathrm{La} / \mathrm{Sm})\left(\right.$ from -0.24 for $\mathrm{REE} / \mathrm{C}=2.7 .10^{-2}$ to -0.41 for $\mathrm{REE} / \mathrm{C}=$ $\left.4.10^{-4}\right)$

$\log \mathrm{K}_{d}$ and $\log (\mathrm{REE} / \mathrm{C})$ display good negative linear correlations $\left(\mathrm{R}^{2}>0.99\right)$ when reported together (e.g., La, Lu; Fig. 2) within the tested REE/C range. The $\log \mathrm{K}_{d}^{\mathrm{REE}}$ increase 
1 with the decreasing metal loading demonstrated the non-linearity of the REE-HA binding

2 involved by the HA binding site heterogeneity. Slopes of $\log \mathrm{K}_{\mathrm{d}}^{\mathrm{REE}}$ versus $\log \mathrm{REE} / \mathrm{C}$ noted

$3 \mathrm{a}_{\mathrm{i}}$, $(\mathrm{i}=\mathrm{La}$ to $\mathrm{Lu})$ which corresponds to the non linearity coefficient of the REE-HA binding

4 increase regularly along the REE series, suggesting that HREE binding to HA is strongly

5 influenced by the HA site heterogeneity (Fig. 3). Our results demonstrate that REE-HA

6 binding occurs through high density but weak HA sites at high metal loading, implying a

7 concave $\log \mathrm{K}_{\mathrm{d}}^{\mathrm{REE}}$ pattern. By contrast, at low metal loading, REE and notably HREE are

8 preferentially bound to strong affinity but low density HA sites, which involves a regular

$9 \quad \log \mathrm{K}_{\mathrm{d}}^{\mathrm{REE}}$ increase from La to $\mathrm{Lu}$.

\subsection{Calculating $\log K_{M A}$ and $\Delta L K 2$ values}

Calculations are performed using the computer program WHAM 6 (Version 6.0.13), which includes Model VI. We used a classic strategy that consists of adjusting the intrinsic parameters of the model to each REE simultaneously until the minimization of the root mean square error (rmse). We not only adjust $\log \mathrm{K}_{\mathrm{MA}}$ (i.e. the parameter that quantifies REE complexation via the high-density, low-affinity sites), but also the $\Delta \mathrm{LK}_{2}$ values. $\Delta \mathrm{LK}_{2}$ is the parameter that addresses the non-linearity of the cation-HA binding in Model VI and is used to increase HA strong site influence on the binding. Tipping (2002) designate $\Delta \mathrm{LK}_{2}$ as "the strong binding site term". This procedure is a unique feature of the present study, as all previous workers have considered this parameter as constant and equal to 0.29 for each individual REE (e.g. Pourret et al., 2007b). Pourret et al.'s (2007b) log $\mathrm{K}_{\mathrm{MA}}$ dataset was used as initial $\log \mathrm{K}_{\mathrm{MA}}$ values. Considering that $\Delta \mathrm{LK}_{2}$ and $\left|\mathrm{a}_{\mathrm{i}}\right|$ coefficient represent both the non linearity of the REE-HA binding and the subsequent HA site heterogeneity, $\Delta \mathrm{LK}_{2}$ values were optimised assuming a linear correlation with $\mathrm{a}_{\mathrm{i}} .\left(\Delta \mathrm{LK}_{2}=2.98 * \mathrm{a}_{\mathrm{i}}-1.88\right)$. 
Table 2 reports the two sets of optimized $\log \mathrm{K}_{\mathrm{MA}}$ and $\Delta \mathrm{LK}_{2}$ values thus obtained for

2 the 14 analysed REE. As indicated, by rmse values $(<0.03)$, the fits can be considered of good

3 quality. The optimized $\Delta \mathrm{LK}_{2}$ values are intermediate between the values for trivalent $\mathrm{Al}$ and

4 Fe (0.46 and 2.20, respectively) determined by Tipping et al. (2002). The new set of 5 optimized $\log \mathrm{K}_{\mathrm{MA}}$ values is compared with the earlier dataset published by Pourret et al.

6 (2007b) (Table 2). The new values are higher than the previous results by ca. $0.1 \log$ unit.

7 They are also distinguished by the presence of a slight but continuous decrease of Log $\mathrm{K}_{\mathrm{MA}}$

8 from Dy to Lu. The optimized $\log \mathrm{K}_{\mathrm{MA}}$ and $\Delta \mathrm{LK}_{2}$ values reported in Table 2 are used to draw

9 the calculated $\mathrm{La}$ and $\mathrm{Lu}$ adsorption isotherm (Fig. 4a) as well as $\log (\mathrm{La} / \mathrm{Sm})$ and $\log$ $10(\mathrm{Gd} / \mathrm{Yb})$ variations vs. $\log (\mathrm{REE} / \mathrm{C})$ (Fig. 4b). The comparison between calculated and 11 experimental data shows a reasonably good fit which demonstrates the ability of Model VI to 12 predict the REE-HA binding at high and low REE/C. In particular, calculated log $(\mathrm{La} / \mathrm{Sm})$ and $13 \log (\mathrm{Gd} / \mathrm{Yb})$ decrease with decreasing $\log (\mathrm{REE} / \mathrm{C})$, in the same way as the experimental 14 values (Fig. 4b).

\section{DISCUSSION}

\subsection{Comparison with the literature}

In Model VI, the log $\mathrm{K}_{\mathrm{MA}}$ values may be regarded as representing the binding characteristics of weak sites controlling REE complexation with $\mathrm{HA}$ at high $\mathrm{REE} / \mathrm{C}$.

20 Although, these values do not represent stability constants, the relative variation of $\log \mathrm{K}_{\mathrm{MA}}$ through the REE series likely reflects the ability of the weak sites to bind REE. Thus, the weak sites may be considered as preferentially complexing the MREE whereas the strong

23 sites, whose complexation constant depend on $\Delta \mathrm{LK}_{2}$, may be regarded as preferentially complexing HREE rather than MREE or LREE. 
In Figure 5a, the optimized $\log \mathrm{K}_{\mathrm{MA}}$ values were compared with the $\log \mathrm{K}_{\mathrm{MA}}$ values

2 reported earlier by Pourret et al. (2007b), as well as with the conditional stability constants

$3(\log \beta)$ published by Yamamoto et al. (2009b). Both published datasets were computed from

4 high metal loading experiments $\left(3.10^{-3}<\mathrm{REE} / \mathrm{C}<3.10^{-2}\right)$ in which the REE behaviour should

5 be determined by the weak sites. This comparison is interesting since the three datasets were

6 obtained using different experimental techniques, namely: ultrafiltration in the present study

7 and Pourret et al.'s datasets (2007b), as against solvent extraction for the dataset reported by

8 Yamamoto et al. (2009b). Quite clearly, the three data sets exhibit similar patterns,

9 characterized by the same strong MREE downward concavity. The apparent decrease of the

10 optimized $\log \mathrm{K}_{\mathrm{MA}}$ from $\mathrm{Dy}$ to $\mathrm{Lu}$ is a consequence of the high $\Delta \mathrm{LK}_{2}$ values introduced into

11 Model VI to accurately describe REE binding by HA. Optimized $\Delta \mathrm{LK}_{2}$ values computed from

12 the new experimental data are not only different for each REE (varying from 1.1 to 2.1), but

13 also much higher than the common value of 0.29 adopted by users of Model VI (i.e. Pourret et al., 2007b; Yamamoto et al., 2009b).

In Figure 5b, log K pattern of REE-HA fewest and strongest site occurring in Model VI (i.e. $0.9 \%$ of $\mathrm{T} 16$ site, whose $\log \mathrm{K}$ is increased by $3 \times \Delta \mathrm{LK}_{2}$ in Tipping, 1998), noted log $\mathrm{K}(\mathrm{REE}-\mathrm{T} 16)$, is compared to that of $\log \beta$ reported by Sonke and Salters (2006) and Yamamoto et al. (2009b) for low metal loading experiments. All patterns are characterized by 19 a continuous increase from $\mathrm{La}$ to $\mathrm{Lu}$. This similarity is considered as confirming that the $\Delta \mathrm{LK}_{2}$ values computed here can be used to model the role of strong sites controlling REE 21 binding at low REE/C.

\subsection{Impact of $\Delta \mathrm{LK}_{2}$ values on modelling results at high to low $\mathrm{REE} / \mathrm{C}$}

To obtain further insight into the influence of the $\Delta \mathrm{LK}_{2}$ parameter in calculating REE 
1 than present experimental ratios, using (i) the low and common $\Delta \mathrm{LK}_{2}$ value of 0.29 proposed

2 by Tipping (1998) for each REE (simulation 1), and (ii) the optimized $\Delta \mathrm{LK}_{2}$ (simulation 2). In

3 these simulations, the HA concentration, the $\mathrm{pH}$ and the ionic strength of the solution are kept

4 constant and equal to $10 \mathrm{mg} \mathrm{L}^{-1}, 3$, and $10^{-2} \mathrm{M} \mathrm{NaCl}$, respectively. Rare earth element

5 concentration ranges from $10^{-5}$ to $10^{-12} \mathrm{M}$. These simulations were carried out to determine

6 quantitatively the bias introduced under low REE/C ratio conditions by using the $\Delta \mathrm{LK}_{2}$ value

7 of 0.29 . Moreover, this approach is also a way of emphasizing and quantifying the role of

8 strong binding sites in controlling REE binding with HA at low to high REE/C ratio. The

9 common use of the $\Delta \mathrm{LK}_{2}$ value of 0.29 leads to a huge underestimation of REE bound to HA

10 when the REE/C becomes lower than ca. $10^{-4}$, as compared to the predictions performed with

11 the optimized $\Delta \mathrm{LK}_{2}$ values. For La, the underestimation ranges from ca. $0.4 \log$ units for

$\mathrm{REE} / \mathrm{C}$ of ca. $10^{-4}$ up to ca 1.5 for REE/C of ca. $10^{-7}$. The underestimation is even higher for

13 Lu: from ca. $1 \log$ units for REE/C of ca. $10^{-4}$ up to ca. 3.5 for REE/C of ca. $10^{-7}$. The higher

14 underestimation obtained for $\mathrm{Lu}$ is consistent with the fact that the optimized $\Delta \mathrm{LK}_{2}$ values,

15 which must be introduced in Model VI to account for the strong REE-binding sites, are much

16 higher for $\mathrm{Lu}$ (2.1) than for $\mathrm{La}$ (1.1). In agreement with this behaviour, and as illustrated in

17 Figure 6, the use of a low and constant $\Delta \mathrm{LK}_{2}$ value of 0.29 as proposed by Tipping (1998)

18 would lead to an underestimation of the fraction of the REE bound to HA under low REE/C

19 conditions. More importantly, $\Delta \mathrm{LK}_{2}$ values of 0.29 would also produce a biased $\log \mathrm{K}_{\mathrm{d}}^{\mathrm{REE}}$

20 pattern that remains concave whatever the metal loading.

\subsection{Nature of the binding sites}

Previous studies have shown that the downward concavity of $\log \mathrm{K}_{\mathrm{MA}}$ or/and $\log \beta$

24 patterns obtained from high $\mathrm{REE} / \mathrm{C}$ experiments is also apparent in the patterns for simple 
1 organic compounds possessing carboxylic functional groups such as acetic acid (Fig. 7a;

2 Yamamoto et al., 2005, and Pourret et al., 2007b). As stated above, the weak sites that control

3 the binding of REE to humic substances at high REE/C are likely to be carboxylic functions, a

4 hypothesis supported by the C 1s-NEXAFS analyses of saturated Eu-HA complexes

5 published by Plaschke et al. (2004). This implies that simple organic compounds having

6 carboxylic functional groups such as acetate (e.g. Byrne and Li, 1995) can be regarded as

7 analogues of these weak sites.

A similar comparative approach may provide information about the nature of the strong sites. High-affinity sites in HA are generally thought to comprise phenolic functions and/or multi-dentate carboxylic (Takahashi et al., 1997; Stern et al., 2007; Pourret and Martinez, 2009). Amine sites are known to be involved in the complexation of Am (III) and $\mathrm{Cu}$ (II) by HA (Peters et al., 2001; Wu and Tanoue, 2001), so they could be also involved in strong binding sites. Due to the high pKa of HA phenolic sites (around 9; Ritchie and Perdue, 2003), it is unlikely that strong sites correspond to phenolic sites given the low $\mathrm{pH}$ value $(\mathrm{pH}$ $=3$ ) of the present experiments. Stability constant patterns of REE-phosphate, REE-oxalic acid and REE-NTA complexes exhibit the same lanthanide contraction effect than the $\log \mathrm{K}$ of the REE-HA strongest sites occurring in Model VI (REE-T16) complexes (Byrne and Sholkovitz, 1996; Schijf and Byrne, 2001; Takahashi et al., 2007; Fig. 7b). Rare earth element binding to oxalic acid and NTA occurs either through multicarboxylic sites or multicarboxylic $\mathrm{N}$-containing sites. Given the similarity of the stability constant patterns, the strong sites that control REE binding at low REE/C might be similar to simple multicarboxylic sites, or multicarboxylic sites containing amino or, possibly, phosphate binding groups.

Finally, the new Log $\mathrm{K}_{\mathrm{MA}}$ and $\log \mathrm{K}$ (REE-T16) patterns were also compared with patterns of REE binding to bacteria cells (B. Subtilis; Takahashi et al., 2007; see Fig. 7a). These patterns are interesting because they combine the binding features of the strong and 
1 weak sites of HA, namely a relative enrichment of the HREE and a middle downward

2 concavity of the MREE. As observed in the present study, Takahashi et al. (2007) found that,

3 with decreasing metal loading, the $\log \mathrm{K}_{\mathrm{d}}^{\mathrm{HREE}}$ between the bacteria suspension and the

4 experimental solution increased more strongly than the $\log \mathrm{K}_{\mathrm{d}}^{\mathrm{LREE}}$ (Fig. 1, and Fig. 2 in

5 Takahashi et al., 2007). More recently, Takahashi et al. (2008) demonstrated that the binding

6 of the LREE and of the HREE at the surface of bacteria involved two types of sites:

7 monodentate phosphate sites for the LREE and multidentate phosphate sites (alkylphosphates)

8 for the HREE. Although bacteria cells cannot be compared to HA, it is a striking observation

9 that similar variations in metal loading led to similar changes in REE binding capacity and a similar fractionation of REE distribution patterns.

To conclude, this literature review suggests that the few strong sites activated at low $\mathrm{REE} / \mathrm{C}$ in REE binding with HA could be multidentate carboxylic sites, or perhaps $\mathrm{N}-$, or P-

functional groups. The identification of the exact nature of these sites clearly remains a challenging issue. To solve this problem, further detailed high-resolution spectroscopic investigations of REE-HA complexes involving, for example, EXAFS studies are required.

\subsection{Is there any evidence for a metal loading effect in natural organic-rich waters?}

There is now ample evidence that humic substances (HS) control REE speciation in natural organic-rich waters (Bidoglio et al., 1991; Takahashi et al., 1997; Glaus et al., 1995; Viers et al., 1997; Dia et al., 2000; Glaus et al., 2000; Gruau et al., 2004; Johannesson et al., 2004; Davranche et al., 2005; Yamamoto et al., 2005; 2006; 2009b; Sonke and Salters, 2006; Pourret et al., 2007a, b; Stern et al., 2007; Davranche et al., 2008; Pédrot et al., 2008; Yamamoto et al., 2009b). Speciation studies show that nearly $100 \%$ of the REE occur as organic complexes in such waters (Viers et al. 1997, Dia et al., 2000; Tang and Johannesson, 2003; Gruau et al., 2004; Johannesson et al., 2004; Pourret et al., 2007b; Pédrot et al., 2008). Yet, REE patterns are highly variable in these waters. As shown on Figure 8, which presents a 
1 compilation of REE data for $<0.2 \mu \mathrm{m}$ filtered organic-rich waters, $\log (\mathrm{La} / \mathrm{Sm})_{\mathrm{UCC}}$ and $\log$

$2(\mathrm{Gd} / \mathrm{Yb})_{\mathrm{UCC}}$ values vary by ca. 0.5 and $0.8 \log$ units in such waters, respectively, reflecting

3 strong fractionation of the REE patterns. All the waters compiled in Figure 8 have DOC

4 concentrations $>5 \mathrm{mg} \mathrm{L}^{-1}$, and $\mathrm{pH}$ values in the range 4 to 7 . This implies that the REE pattern

5 in these waters must be controlled, at least in part, by the binding affinities of the organic

6 molecules REE binding sites. Given the results presented in this study, we are led to pose the

7 following question: could the variation in REE pattern displayed by natural organic-rich

8 waters be due to the metal loading effect?

Addressing this question is not a trivial task because of the $\mathrm{pH}$ dependence of the metal loading effect, and the chemical composition variability of these waters. Nevertheless,

11 we can note the following two features which allow us to consider this possibility. Figure 8 presents a compilation of 350 samples of organic-rich, river-, and soil-waters. Besides the strong variability of the REE pattern, Figure 8 shows that organic-rich waters are not randomly distributed when plotted in a $\log (\mathrm{La} / \mathrm{Sm})_{\mathrm{UCC}}$ versus $\log (\mathrm{Gd} / \mathrm{Yb})_{\mathrm{UCC}}$ diagram. Indeed, the data points are almost entirely restricted to the upper and lower left-hand corners of the diagram, illustrating that REE patterns in organic-rich waters range from patterns showing a MREE downward concavity to patterns showing a continuous enrichment from La to Lu. Only a very small number of waters (7 out of a total of 350) display patterns exhibiting a continuous enrichment from Lu to La, or showing a MREE upward concavity. This nonrandom distribution of REE patterns in organic-rich waters was already pointed out by

21 Pourret et al. (2007b), although based on a compilation pooling a far more limited number of waters (Fig. 6 in Pourret et al., 2007b). Figures 9a and 9b plotting $\log (\mathrm{La} / \mathrm{Sm})_{\mathrm{UCC}}$ and $\log$ $23(\mathrm{Gd} / \mathrm{Yb})_{\mathrm{UCC}}$ against log $(\mathrm{REE} / \mathrm{C})$, respectively, display both $(\mathrm{La} / \mathrm{Sm})_{\mathrm{UCC}}$ and $\log (\mathrm{Gd} / \mathrm{Yb})_{\mathrm{UCC}}$ decrease with decreasing metal loading which is consistent with the present experimental results, HREE-HS and MREE-HS binding being favoured at low and high metal loading, 
1 respectively. Therefore, natural waters with low REE/C should exhibit an HREE-enriched

2 REE pattern, by contrast to high REE/C waters which should display a MREE-enriched REE

3 pattern. The dispersion of data observed in Figures 8 and 9 may be attributed to two major

4 uncertainties. (i) The metal loading should be expressed as $\log (\mathrm{M} / \mathrm{C})$ where $\mathrm{M}$ represents the

5 sum of the dissolved cations that compete with REE for HS surface sites. However, because

6 metallic nano-oxides ( $\mathrm{Fe}$ or $\mathrm{Al}$ ) may be included in the $<0.2 \mu \mathrm{m}$ water fraction, (e.g.

7 Pokrovsky et al. 2006; Pédrot et al., 2009), log (M/C) could be overestimated. By contrast,

8 published chemical water compositions often lack the entire cation content, which

9 consequence could be an underestimation of the $\log (\mathrm{M} / \mathrm{C})$.(ii) REE distribution may also be

10 strongly influenced by the surface functional group heterogeneity and density of the different

11 HS types. Although these uncertainties, REE distributions in Figures 8 and 9 do correspond to

12 the expected distributions if the REE pattern shape prevailing in organic-rich waters is 13 controlled by a metal loading effect.

14 Thus, the special fractionation of REE patterns in natural organic-rich waters suggests

15 that the metal loading effect could be the cause of the marked variability of REE patterns that

16 characterize these systems. As a whole, the present investigation, when combined with results

17 from previous studies by Yamamoto et al. (2005; 2009b), Sonke and Salters (2006), Stern et

18 al. (2007) and Pourret et al. (2007b) demonstrates that: (i) HA binding site heterogeneity

19 (strong and weak sites) directly influences the REE complexation patterns, and (ii) this latter

20 point may be explained by a loading effect: at low metal loading, stronger sites are favoured

21 yielding HREE-enriched REE patterns, whereas, at high metal loading, the more abundant

22 weaker sites dominate complexation leading to REE patterns with MREE downward 23 concavity. 


\section{CONCLUSIONS}

The effect of metal loading on the binding of the rare earth elements (REE) to humic acid (HA) was studied by combining ultrafiltration and Inductively Coupled Plasma Mass Spectrometry techniques. REE-HA binding experiments were performed at $\mathrm{pH} 3$ for $\mathrm{REE} / \mathrm{C}$ ranging from ca $4.10^{-4}$ to $2.7 \cdot 10^{-2}$, using a standard batch equilibration method. Results show that the relative amount of REE bound to HA strongly increases with decreasing REE/C. Moreover, a middle-REE (MREE) downward concavity is displayed by $\log \mathrm{K}_{\mathrm{d}}^{\mathrm{REE}}$ patterns at high metal loading, whereas patterns at low metal loading exhibit a regular increase from La to $\mathrm{Lu}$. These results demonstrate that the variability of REE-HA binding patterns published so far (Yamamoto et al., 2005; 2006; 2009b; Sonke and Salters, 2006; Pourret et al., 2007b; Stern et al., 2007) is not an artefact resulting from the use of different analytical procedures. The variability of patterns is real, reflecting the presence of two types of sites in HA surface, each occurring in markedly distinct proportions and each having different binding affinities for the REE. The resulting metal loading effect explains the variation of $\log \mathrm{K}_{\mathrm{d}}^{\mathrm{REE}}$ patterns with changing REE/C. the binding of REE with HA can be defined by the Model VI intrinsic log $\mathrm{K}_{\mathrm{MA}}$ and $\Delta \mathrm{LK}_{2}$ parameters, $\Delta \mathrm{LK}_{2}$ parameter being free to vary among the REE series. Optimization of both parameters provides evidence that high density but weak sites determine the distribution of REE to HA at high REE/C, favouring the complexation of the MREE. By contrast, the few strong sites determine the distribution of REE to HA at low REE/C, favouring the HREE complexation. A literature review suggests that the few strong sites activated at low REE/C could be multidentate carboxylic sites, or perhaps $\mathrm{N}$-, or P-functional groups, whereas the weak sites involved at high metal loading are likely to be monodendate carboxylic sites. 
1 Application of Model VI to the experimental data shows that this model closely reproduces

2 the observed variations. Hence, this model is a very powerful tool for studying and taking into

3 account the loading effect that controls REE binding by HA.

Finally, confronting the variability of REE patterns in natural organic-rich waters and their metal loading level, expressed as REE/C, shows that the loading effect discussed here

6 could explain part of the shape variability of REE patterns observed in these waters. Overall, 7 our results suggest that further factors, such as competitive cations and/or colloidal nano8 oxides, should be considered to improve the metal loading effect accuracy. Also the

9 variability of humic substances chemical composition should be considered to explain the diversity of the binding sites that may be involved in REE complexation mediated by organic matter. These other factors should be taken into account to model and thus better understand REE cycling and transport in natural systems. Once again, Model VI may provide a reliable and powerful tool for this purpose.

Acknowledgments. We thank the technical staff at Géosciences-Rennes (M. Le Coz-

Bouhnik, P. Petitjean and O. Hénin) for their assistance during both sample preparation and chemical analyses. Dr. Y. Takahashi, Dr. M. I. Leybourne and an anonymous reviewer are thanked for thorough and constructive comments of an earlier version of this paper. This research was funded by the French ANR, through the 'Programme Jeunes Chercheuses Jeunes Chercheurs' and the project: 'SURFREE: Rare earth elements partitioning at solidwater interface: Impact on REE geochemical behaviour and tracing properties'. M.S.N.

21 Carpenter post-edited the English style. 


\section{References}

Abate G. and Masini J.C. (2002) Complexation of Cd(II) and Pb(II) with humic acids studied by anodic stripping voltammetry using differential equilibrium functions and discrete site models. Org. Geochem. 33, 1171-1182.

Auterives C. (2007) Influence des flux d'eau souterraine entre une zone humide superficielle et un aquifère profond sur le fonctionnement hydrochimique des tourbières : exemple des marais du Cotentin, Basse-Normandie. Ph.D thesis. University of Rennes I (France).pp 261.

Benedetti M. F., Milne C. J., Kinniburgh D. G., van Riemsdijk W. H., and Koopal L. K. (1995) Metal-ion binding to humic substances: application of the nonideal competitive adsorption model. Environ. Sci. Technol. 29, 446-457.

Bidoglio G., Grenthe I., Qi P., Robouch P. and Omentto N. (1991) Complexation of Eu and $\mathrm{Tb}$ with fulvic acids as studied by time-resolved laser-induced fluorescence. Talanta $\mathbf{3 8}$ (9), 999-1008.

Buschmann J. and Sigg L. (2006) Arsenite and arsenate binding to dissolved humic acids: Influence of pH, type of humic acid, and aluminum. Environ. Sci. Technol. 40 (19), 60156020.

Buschmann J., Kappeler A., Lindauer U., Kistler D., Berg M. and Sigg L. (2004) Antimony(III) binding to humic substances: Influence of $\mathrm{pH}$ and type of humic acid. Environ. Sci. Technol. 38 (17), 4535-4541.

Byrne R. H. and Li B. (1995) Comparative complexation behaviour of the rare earth elements. Geochim. Cosmochim. Acta 59, 4575-4589.

Byrne R.H. and Sholkovitz E.R. (1996) Marine chemistry and geochemistry of the lanthanides. Handbook on the Physics and Chemistry of Rare Earths 23. Elsevier, Amsterdam, 497-593. 
Davranche M., Pourret O., Gruau G., Dia A. and Le Coz-Bouhnik M. (2005) Adsorption of REE(III)-humate complexes onto $\mathrm{MnO}$ 2: experimental evidence for cerium anomaly and lanthanide tetrad effect suppression. Geochim. Cosmochim. Acta 69, 4825-4835.

Davranche M., Pourret O., Gruau G., Dia A., Jin D. and Gaertner D. (2008) Competitive binding of REE to humic acid and manganes.e oxide: impact of reaction kinetics on Ce anomaly development and REE adsorption. Chem. Geol. 247, 154-170.

Dia A., Gruau G., Olivié-Lauquet G., Riou C., Molénat J. and Curmi P. (2000) The distribution of rare-earths in groundwater: assessing the role of source-rock composition, redox changes and colloidal particles. Geochim. Cosmochim. Acta 64, 4131-4151.

Gaillardet J., Viers J. and Dupré B. (2004) Elements in River Waters. In Treatise on geochemistry 5 (ed. E. D. Holland, Turekian, K.K.), 225-263. Elsevier-Pergamon.

Glaus M. A., Hummel W. and Van Loon L. R. (1995) Stability of mixed-ligand complexes of metal ions with humic substances and low molecular weight ligands. Environ. Sci. Technol. 29, 2150-2153

Glaus M.A., Hummel W. and Van Loon L.R. (2000) Trace metal-humate interactions I. Experimental determination of conditional stability constants. Appl. Geochem. 15, 953973.

Gruau G., Dia A., Olivié-Lauquet G., Davranche M. and Pinay G. (2004) Controls on the distribution of rare earth elements in shallow groundwaters. Wat. Res. 38, 3576-3586.

Johannesson K.H., Tang J., Daniels J.M., Bounds W.J. and Burdige D.J. (2004) Rare earth element concentrations and speciation in organic rich blackwaters of the Great Dismal Swamp, Virginia, USA. Chem. Geol. 209, 271-294.

Kinniburgh D. G., van Riemsdijk W. H., Koopal L. K., Borkovec M., Benedetti M. F., and Avena M. J. (1999) Ion binding to natural organic matter: competition, heterogeneity, stoichiometry and thermodynamic consistency. Colloid Surf. A 151, 147-166. 
Pédrot M., Dia A., Davranche M., Bouhnik-Le Coz M., Henin O. and Gruau G. (2008) Insights into colloid-mediated trace element release at soil/water interface. J. Colloid Interface Sci. 325, 187-197.

Peters A., Hamilton-Taylor J. and Tipping E. (2001) Americium binding to humic acid. Environ. Sci. Technol. 35, 3495-3500.

Plaschke M., Rothe J., Denecke M. A., and Fanghänel T. (2004) Soft X-ray spectromicroscopy of humic acid europium(III) complexation by comparison to model substances. J. Electron Spectrosc. Relat. Phenom. 135, 53-65.

Pokrovsky O.S., Schott J. and Dupré B. (2006) Trace element fractionation and transport in boreal rivers and soil porewaters of permafrost-dominated basaltic terrain in Central Siberia. Geochim. Cosmochim. Acta 70, 3239-3260.

Pourret O. and Martinez R. E. (2009) Modelling lanthanide series binding on humic acid. $J$. Colloid Interface Sci. 330, 45-50.

Pourret O., Davranche M., Gruau G. and Dia A. (2007a) Organic complexation of rare earth elements in natural waters: evaluating model calculations from ultrafiltration data. Geochim. Cosmochim. Acta 71, 2718-2735.

Pourret O., Davranche M., Gruau G. and Dia A. (2007b) Rare earth complexation by humic acid. Chem. Geol. 243, 128-141.

Ritchie J.D. and Perdue E.M. (2003) Proton-binding study of standard and reference fulvic acids, humic acids, and natural organic matter. Geochim. Cosmochim. Acta 67, 85-96.

Schijf J. and Byrne R.H. (2001) Stability constants for mono-and dioxalato-complexes of Y and the REE, potentially important species in groundwaters and surface freshwaters. Geochim. Cosmochim. Acta 65, 1037-1046. 
Sonke J.E. and Salters V.J.M. (2006) Lanthanide-humic substances complexation. I. Experimental evidence for a lanthanide contraction effect. Geochim. Cosmochim. Acta 70, $1495-1506$.

Stern J. C., Sonke J. E. and Salters V. J. M. (2007) A capillary electrophoresis-ICP-MS study of rare earth elements complexation by humic acids. Chem. Geol. 246, 170-180.

Takahashi Y., Minai Y., Ambe S., Makide Y., Ambe F. and Tominaga T. (1997) Simultaneous determination of stability constants of humate complexes with various metal ions using multitracer technique. The Science of the Total Environment 198, 61-71.

Takahashi Y., Hirata T., Ozaki T. and Fortin D. (2007) A rare earth element signature of bacteria in natural waters? Chem. Geol. 244 (3-4), 569-583.

Takahashi Y., Yamamoto M., Ozaki T. and Fortin D. (2008) Characterisation of binding sites of metal ions at bacterial cell surface by REE distribution pattern and EXAFS analysis. 8th Annual V M Goldschmidt Conference. Geochim. Cosmochim. Acta 72, A926-A926.

Tang J. and Johannesson K.H. (2003) Speciation of rare earth elements in natural terrestrial waters: assessing the role of dissolved organic matter from the modeling approach. Geochim. Cosmochim. Acta 67, 2321-2339.

Tipping E. (1998) Humic ion-binding model VI: an improved description of the interactions of protons and metal ions with humic substances. Aquatic Geochemistry 4, 3-48.

Tipping E. (2002) Cation binding by humic substances. Cambridge University Press 12, pp. 434.

Tipping E. (2007) Modelling the interactions of $\mathrm{Hg}(\mathrm{II})$ and methylmercury with humic substances using WHAM/Model VI. Appl. Geochem. 22, 1624-1635.

Tipping E., Rey-Castro C., Bryan S.E. and Hamilton-Taylor J. (2002) Al(III) and Fe(III) binding by humic substances in freshwaters, and implications for trace metal speciation. Geochim. Cosmochim. Acta 66, 3211-3224. 
Tosiani T., Loubet M., Viers J., Yanes C., Dupré B. and Tapia J. (2004) Major and trace elements in river borne materials from the Cuyuni Basin (Southern Venezuela): evidence for organo-colloidal control on the dissolved load and element redistribution between the dissolved load and the suspended load, Chem. Geol. 211, 305-334.

Vermeer A.W.P., Van Riemsdijk W.H. and Koopal L.K. (1998) Adsorption of humic acid to mineral particles. 1. Specific and electrostatic interactions. Langmuir 14, 2810-2819.

Viers J., Dupré B., Polvé M., Schott J., Dandurand J.-L. and Braun J.J. (1997) Chemical weathering in the drainage basin of a tropical watershed (Nsimi-Zoetele site, Cameroon): comparison between organic poor and organic-rich waters. Chem. Geol. 140, 181-206.

Viers J., Dupré B., Deberdt S., Braun J. J., Angeletti B., Ndam Ngoupayou J. and Michard A. (2000) Major and traces elements abundances, and strontium isotopes in the Nyong basin rivers (Cameroon): constraints on chemical weathering processes and elements transport mechanisms in humid tropical environments. Chem. Geol. 169, 211-241.

Wu F. and Tanoue E. (2001) Geochemical characterization of organic ligands for copper (II) in different molecular size fractions in Lake Biwa. Japan. Org. Geochem. 32, 1311-1318.

Yamamoto Y., Takahashi Y. and Shimizu H. (2005) Systematics of stability constants of fulvate complexes with rare earth ions. Chem. Lett. 34, 880-881.

Yamamoto Y., Takahashi Y. and Shimizu H. (2006) Interpretation of REE patterns in natural water based on the stability constants. Geochim. Cosmochim. Acta 70, A717-A717.

Yamamoto Y., Takahashi Y. and Shimizu H. (2009a) Speciation of iron in humic substances by X-ray absorption fine structure and its effect on the complexation between humic substances and trace metal ions. Chem. Lett. 38, 278-279.

Yamamoto Y., Takahashi Y. and Shimizu H. (2009b) Systematic change in relative stabilities of REE-humic complexes at various metal loading levels. Geochemical Journal in press. 


\section{Table and Figure Captions}

Table 1. Model VI parameters used for REE binding to humic acid (Tipping, 1998).

Table 2. $\log \mathrm{K}_{\mathrm{MA}}$ and $\Delta \mathrm{LK}_{2}$ values fitted from the experimental data using Model VI. The quality of the fit is determined by the rmse, calculated as $\sqrt{\text { mean }\left(\log v_{\exp }-\log v_{\text {calc }}\right)^{2}}$, where $\nu$ is the amount of REE bound to HA per gram of DOC for experimental and modelled data, respectively. The $\log \mathrm{K}_{\mathrm{MA}}$ data published by Pourret et al. (2007b) are shown for comparison.

Figure 1. Variation of $\log \mathrm{K}_{\mathrm{d}}^{\mathrm{REE}}$ as a function of REE/C. Error bars correspond to standard deviation of triplicates.

Figure 2. Diagram illustrating negative linear correlations between $\log \mathrm{K}_{\mathrm{d}}$ and $\log (\mathrm{REE} / \mathrm{C})$ for $\mathrm{La}$ and $\mathrm{Lu}$. Error bars correspond to standard deviation of triplicates.

Figure 3 Variation of "a" coefficient through the REE series. "a" is a measure of the nonlinearity of the REE-HA binding isotherms, determined by the slope of $\log \mathrm{K}_{d}^{\mathrm{REE}}$ versus $\log (\mathrm{REE} / \mathrm{C})$

Figure 4. Binding of REE by HA. (a) La-HA and Lu-HA binding isotherm, presented for La and $\mathrm{Lu}$, and (b) Variation of $\log (\mathrm{La} / \mathrm{Sm})$ and $\log (\mathrm{Gd} / \mathrm{Yb})$ versus $\log (\mathrm{REE} / \mathrm{C})$. Closed symbols and lines correspond to experimental data and best fits, respectively. Error bars correspond to standard deviation of triplicates. 
Figure 5. REE patterns for apparent REE-HA binding constant obtained from (a) high REE/C experiments (weak sites) and (b) low REE/C experiments (strong sites). Data source: this study for $\log \mathrm{K}_{\mathrm{MA}}$ and $\log \mathrm{K}(\mathrm{REE}-\mathrm{T} 16)$ (log K Model VI strongest site: 0.9\% of T16 site); Sonke and Salters (2006) (Leonardite coal HA; pH = 7); Pourret et al. (2007b) (Aldrich HA); Yamamoto et al. (2009) (Suwannee River HA; pH = 4.7).

Figure 6. Variation of (a) $\log \mathrm{K}_{\mathrm{d}}^{\mathrm{La}}$ and (b) $\log \mathrm{K}_{\mathrm{d}}^{\mathrm{Lu}}$ relative to the $\log (\mathrm{REE} / \mathrm{C})$, on a large range of metal loading. Comparison of Model VI prediction with (1) $\Delta \mathrm{LK}_{2}=0.29$ (dashed line) and (2) with the optimized $\Delta \mathrm{LK}_{2}$ (bold dashed line). Symbols represent experimental data. Error bars correspond to standard deviation of triplicates.

Figure 7. REE patterns comparing the Log $\mathrm{K}_{\mathrm{MA}}$ obtained in this study and log $\mathrm{K}$ published for acetic acid and bacteria cells (Bacillus Subtillis) (a), as well log K(REE-T16), log K Model VI strongest site ( $0.9 \%$ of T16 site);(this study) and $\log$ K of NTA, oxalic acid and phosphate complexes (b). Data source: this study, Byrne and Li (1995); Schijf and Byrne (2001); Takahashi et al. (2007).

Figure 8. Literature compilation of $\log (\mathrm{Gd} / \mathrm{Yb})_{\mathrm{UCC}}$ versus $\log (\mathrm{La} / \mathrm{Sm})_{\mathrm{UCC}}$, illustrating coherent variations of REE pattern, in natural organic-rich river- and soil-waters. The REE patterns indicate the types of REE pattern specific to each corner of the diagram. Data sources: Dia et al. (2000), Viers et al., 2000; Gaillardet et al., 2004; Gruau et al., 2004; Tosiani et al., 2004; Auterives, 2007.

Figure 9. (a) $\log (\mathrm{La} / \mathrm{Sm})_{\mathrm{UCC}}$ and (b) $\log (\mathrm{Gd} / \mathrm{Yb})_{\mathrm{UCC}}$ versus $\log \mathrm{REE} / \mathrm{C}$ for the data compiled in Figure 8. Solid line represents the linear relationship. 


\begin{tabular}{lll}
\hline Parameter & Description & Values \\
\hline $\mathrm{n}_{\mathrm{A}}$ & Amount of type A sites $\left(\mathrm{mol} \mathrm{g}^{-1}\right)$ & $3.310^{-3}$ \\
$\mathrm{n}_{\mathrm{B}}$ & Amount of type B sites $\left(\mathrm{mol} \mathrm{g}^{-1}\right)$ & $0.5 \mathrm{x} \mathrm{n}_{\mathrm{A}}$ \\
$\mathrm{pK}_{\mathrm{A}}$ & Intrinsic proton dissociation constant for type A sites & 4.1 \\
$\mathrm{pK}_{\mathrm{B}}$ & Intrinsic proton dissociation constant for type B sites & 8.8 \\
$\Delta \mathrm{pK}_{\mathrm{A}}$ & Distribution terms that modifies $\mathrm{pK}_{\mathrm{A}}$ & 2.1 \\
$\Delta \mathrm{pK}_{\mathrm{B}}$ & Distribution terms that modifies $\mathrm{pK}_{\mathrm{B}}$ & 3.6 \\
$\log \mathrm{K}_{\mathrm{MA}}$ & Intrinsic equilibrium constant for metal binding at type A sites & Fitted from experimental data \\
$\log \mathrm{K}_{\mathrm{MB}}$ & Intrinsic equilibrium constant for metal binding at type B sites & 3.39 log $\mathrm{K}_{\mathrm{MA}}-1.15$ \\
$\Delta \mathrm{LK}_{1}$ & Distribution term that modifies log $\mathrm{K}_{\mathrm{MA}}$ & 2.8 \\
$\Delta \mathrm{LK}_{2}$ & Distribution term that modifies the strengths of bidentate and tridentate sites & Fitted from experimental data \\
$\mathrm{P}$ & Electrostatic parameter & -330 \\
$\mathrm{~K}_{\text {sel }}$ & Selectivity coefficient for counterion accumulation & 1 \\
$\mathrm{M}$ & Molecular weight & $15000 \mathrm{Da}$ \\
$\mathrm{r}$ & Molecular radius & $1.72 \mathrm{~nm}$ \\
\hline
\end{tabular}

\section{Table 1}




\begin{tabular}{ccccc}
\hline $\mathrm{REE}$ & $\log \mathrm{K}_{\mathrm{MA}}{ }^{(1)}$ & $\log \mathrm{K}_{\mathrm{MA}}{ }^{(2)}$ & $\Delta \mathrm{LK}_{2}{ }^{(2)}$ & $\mathrm{rmse}^{(2)}$ \\
\hline $\mathrm{La}$ & 2.58 & 2.70 & 1.10 & 0.02 \\
$\mathrm{Ce}$ & 2.60 & 2.72 & 1.15 & 0.02 \\
$\mathrm{Pr}$ & 2.61 & 2.73 & 1.20 & 0.02 \\
$\mathrm{Nd}$ & 2.63 & 2.74 & 1.20 & 0.01 \\
$\mathrm{Sm}$ & 2.65 & 2.75 & 1.30 & 0.01 \\
$\mathrm{Eu}$ & 2.65 & 2.74 & 1.35 & 0.01 \\
$\mathrm{Gd}$ & 2.63 & 2.72 & 1.35 & 0.01 \\
$\mathrm{~Tb}$ & 2.62 & 2.71 & 1.50 & 0.01 \\
$\mathrm{Dy}$ & 2.61 & 2.70 & 1.60 & 0.02 \\
$\mathrm{Ho}$ & 2.60 & 2.69 & 1.65 & 0.02 \\
$\mathrm{Er}$ & 2.60 & 2.69 & 1.70 & 0.01 \\
$\mathrm{Tm}$ & 2.59 & 2.67 & 1.90 & 0.01 \\
$\mathrm{Yb}$ & 2.60 & 2.65 & 2.05 & 0.02 \\
$\mathrm{Lu}$ & 2.60 & 2.64 & 2.10 & 0.02 \\
\hline
\end{tabular}

(1) Pourret et al. (2007b)

(2) This study

Table 2 


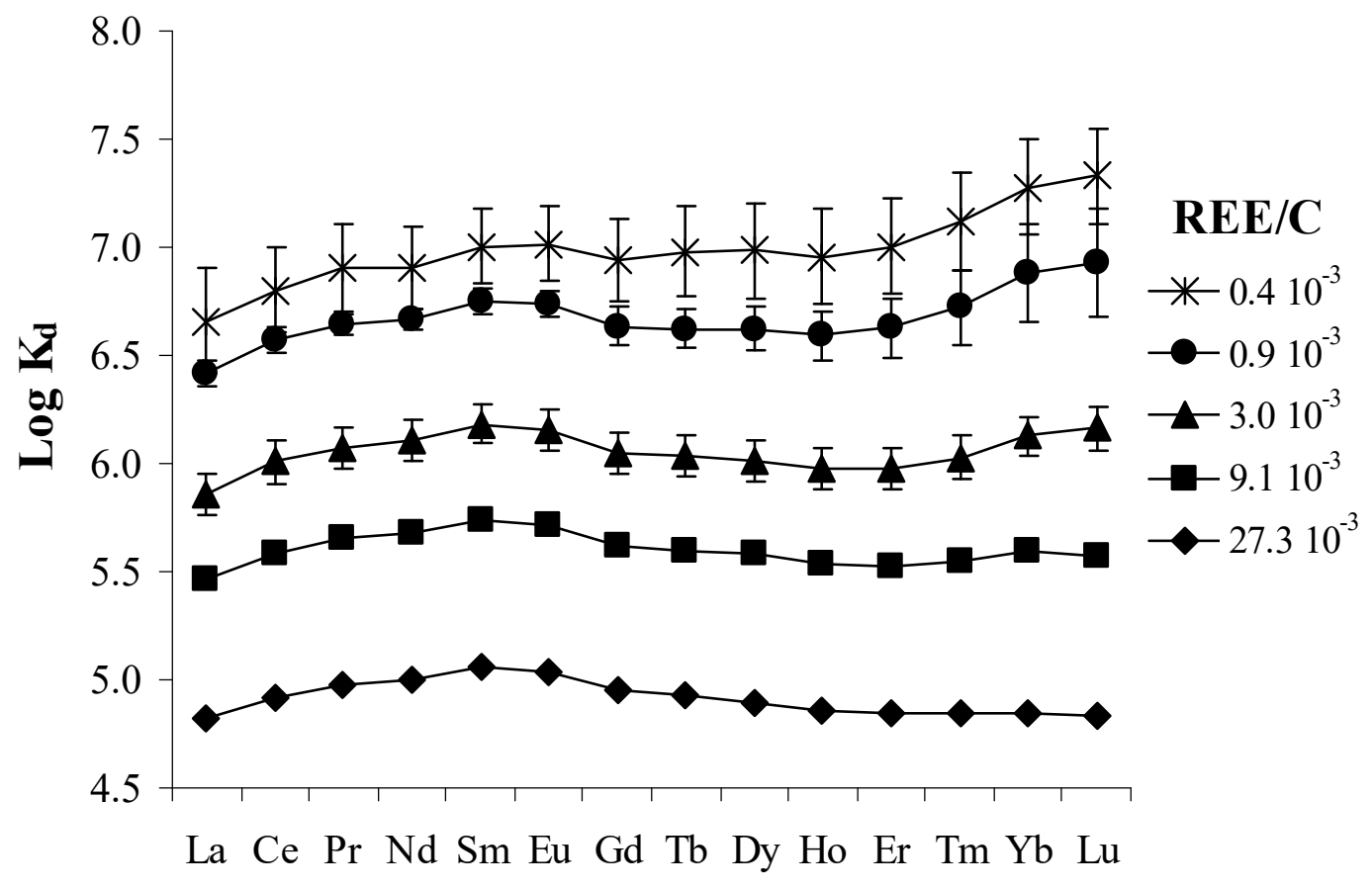

Figure 1 


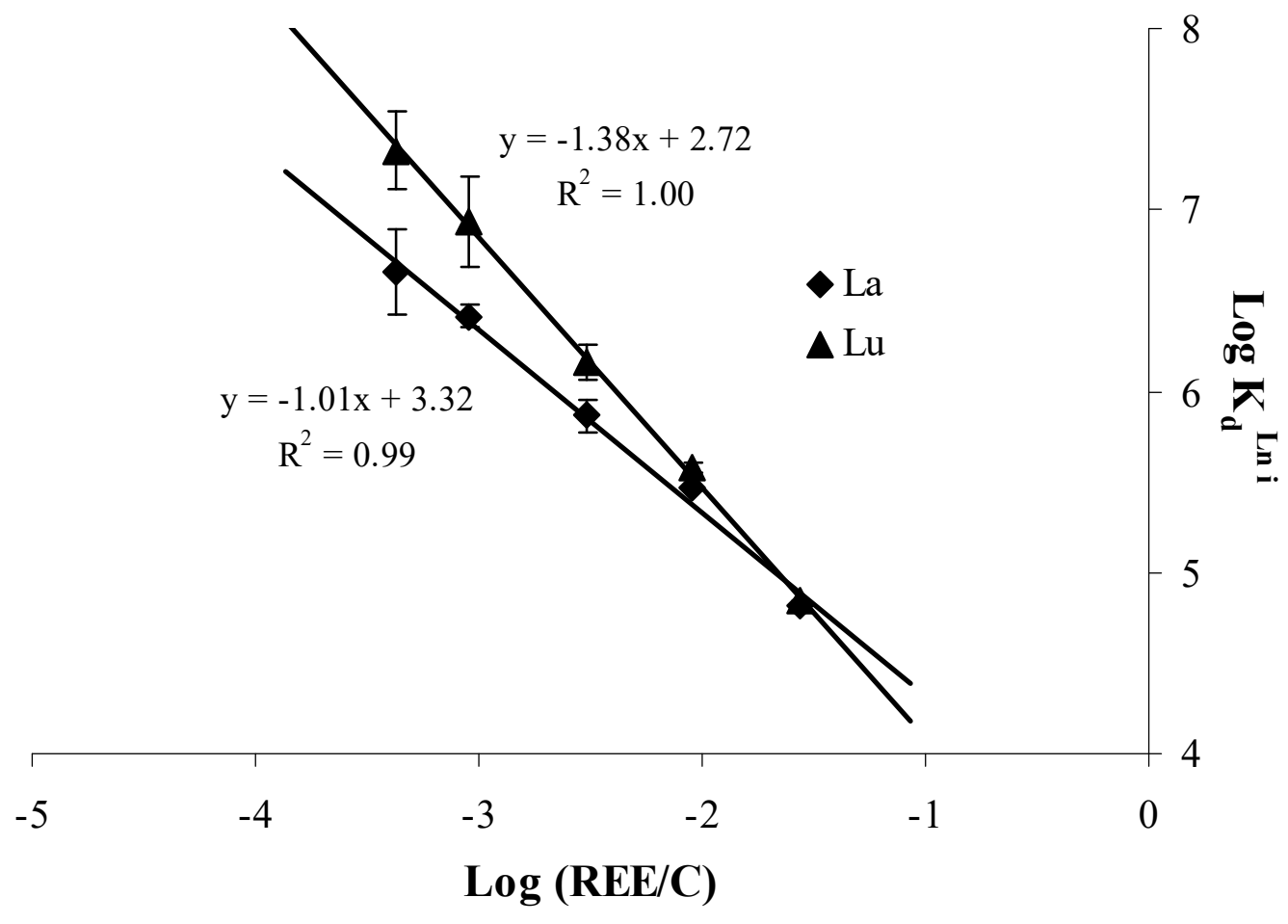

Figure 2 


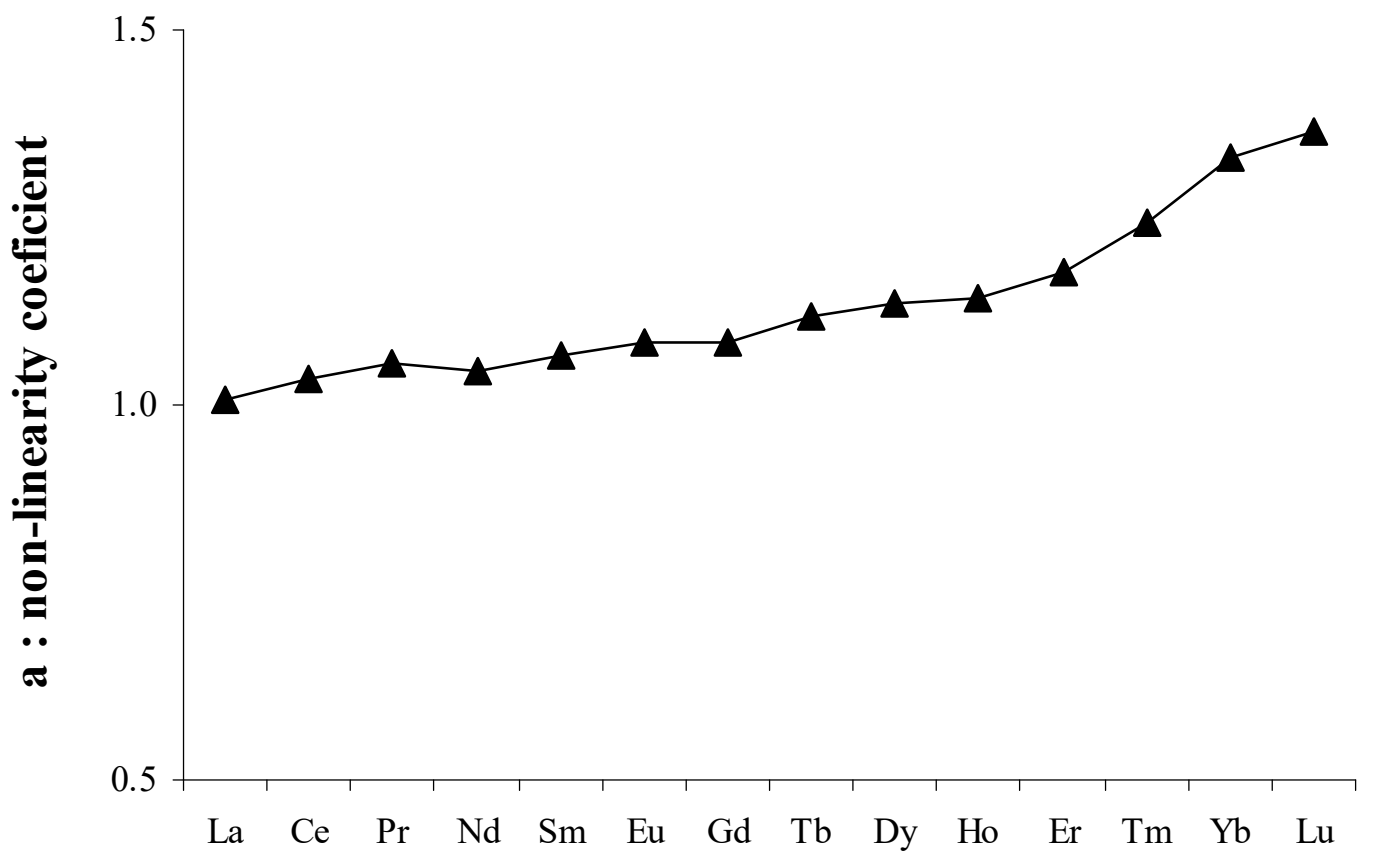

Figure 3 

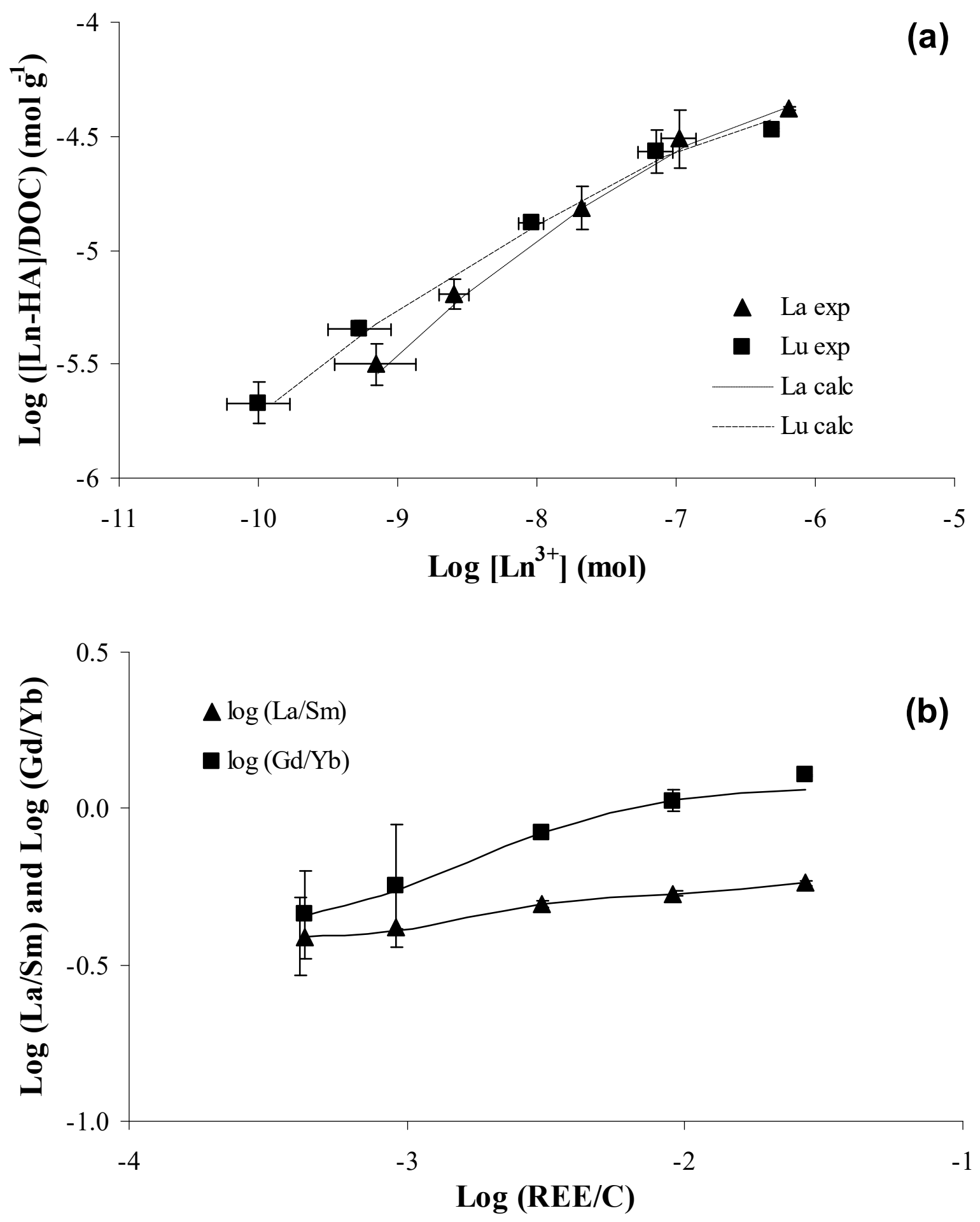

Figure 4 

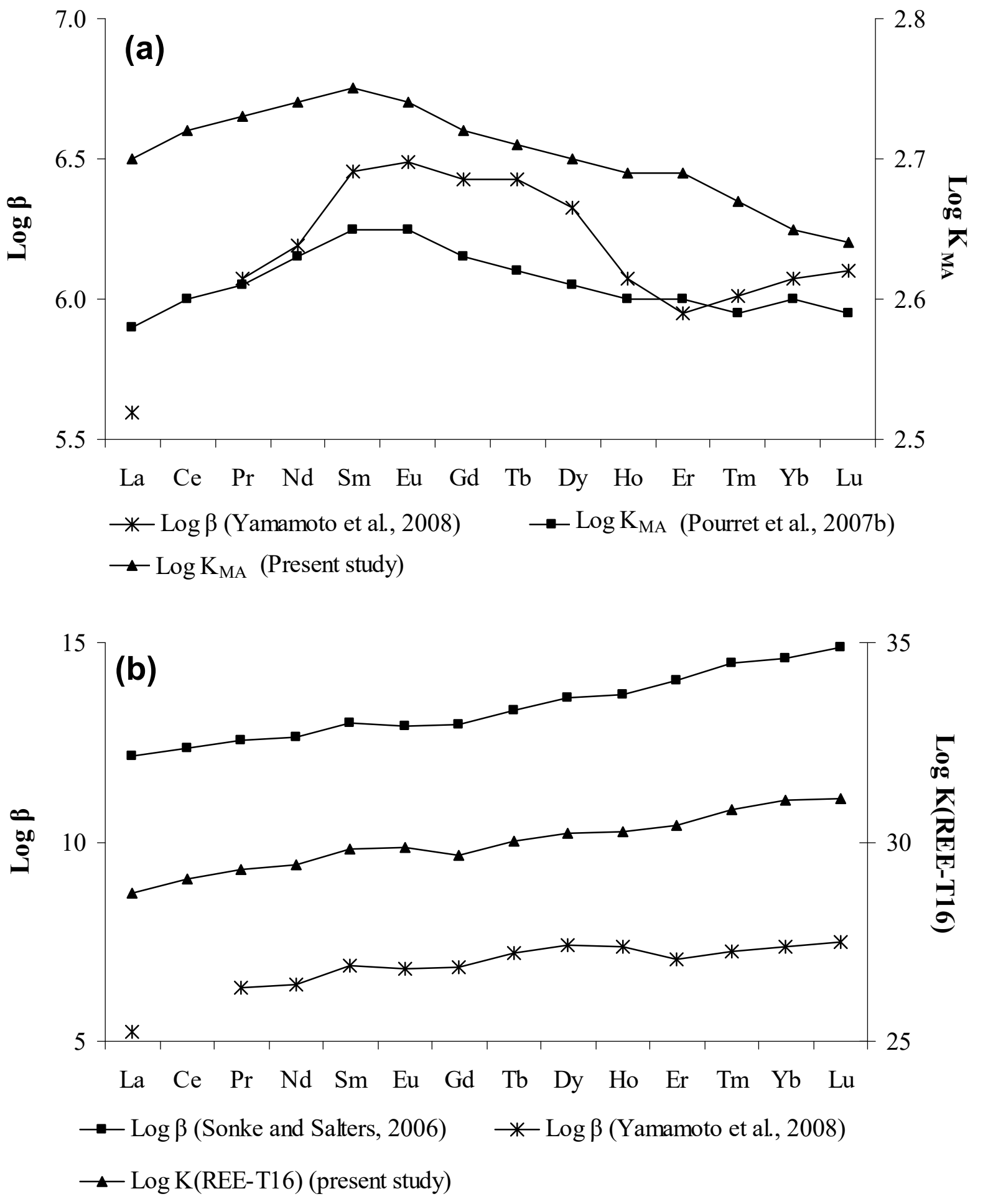

Figure 5 

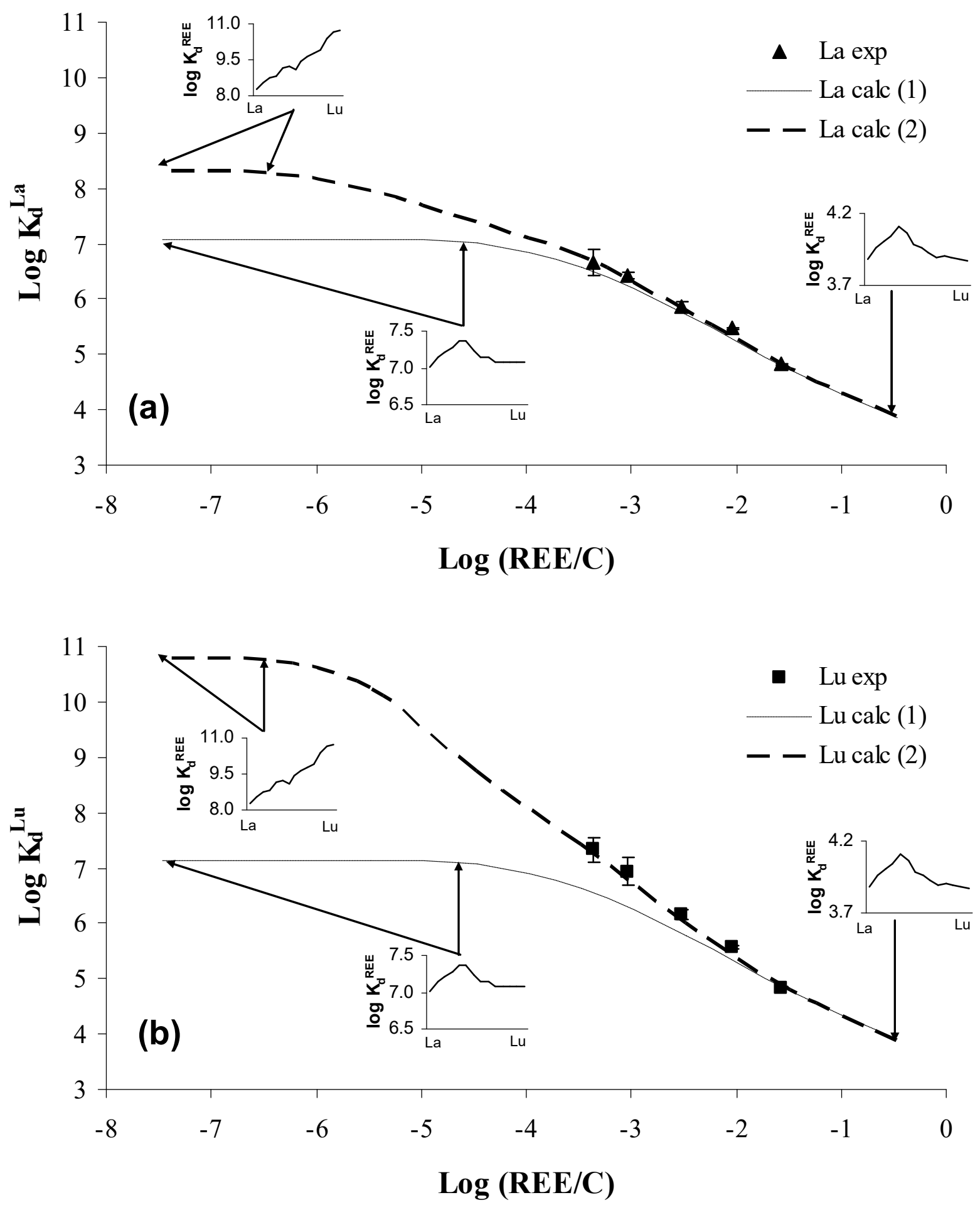

Figure 6 

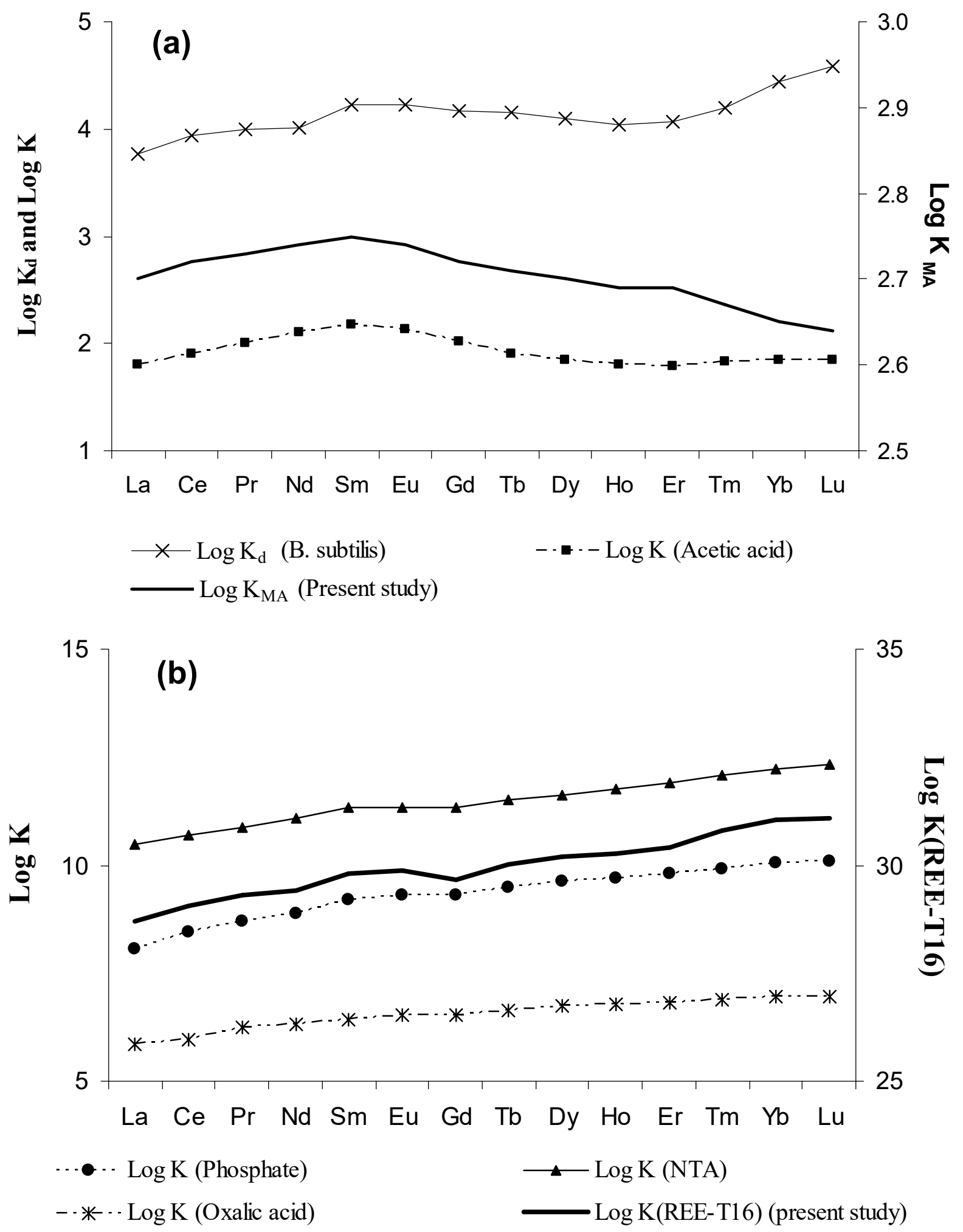

Figure 7 


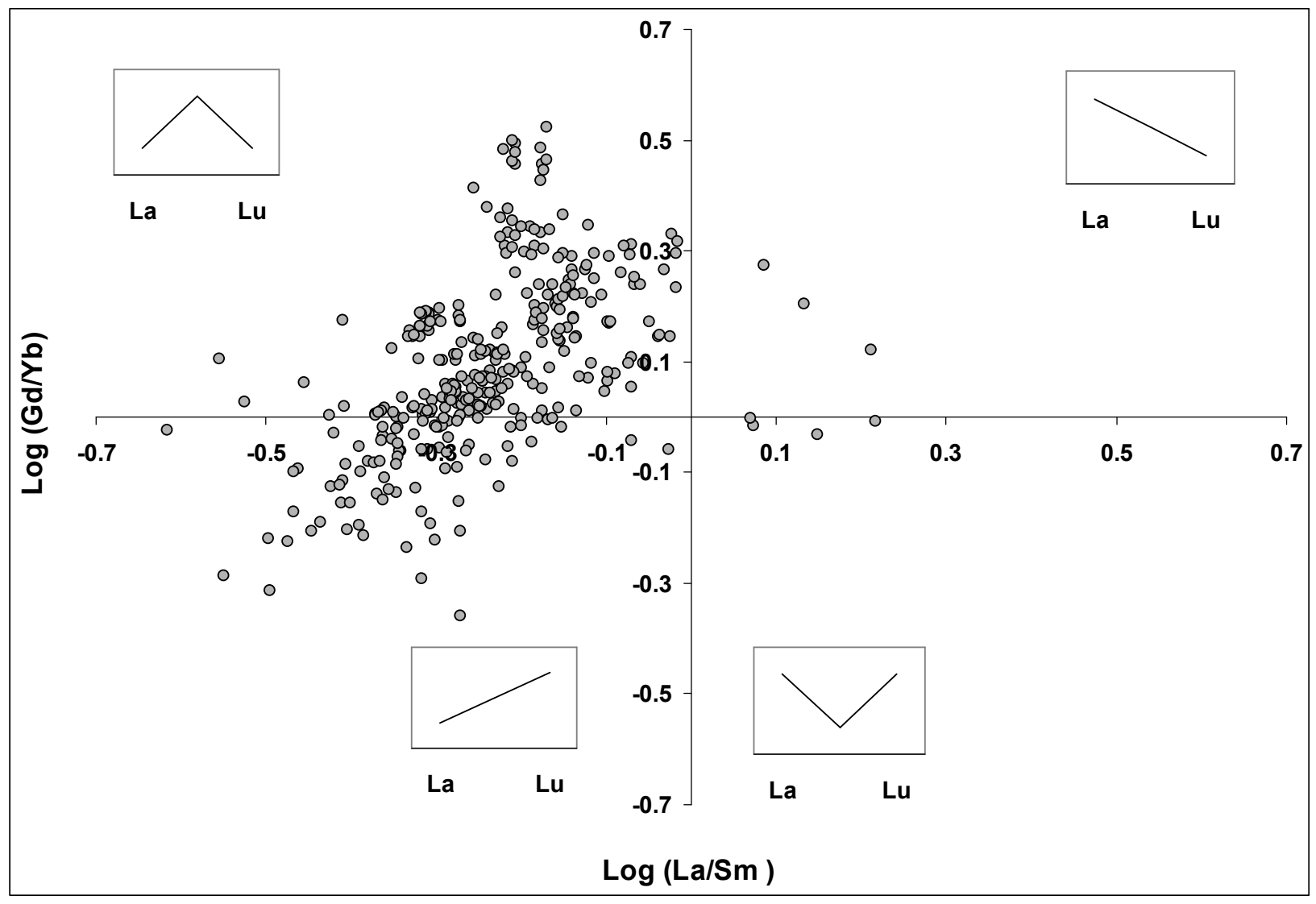

Figure 8 

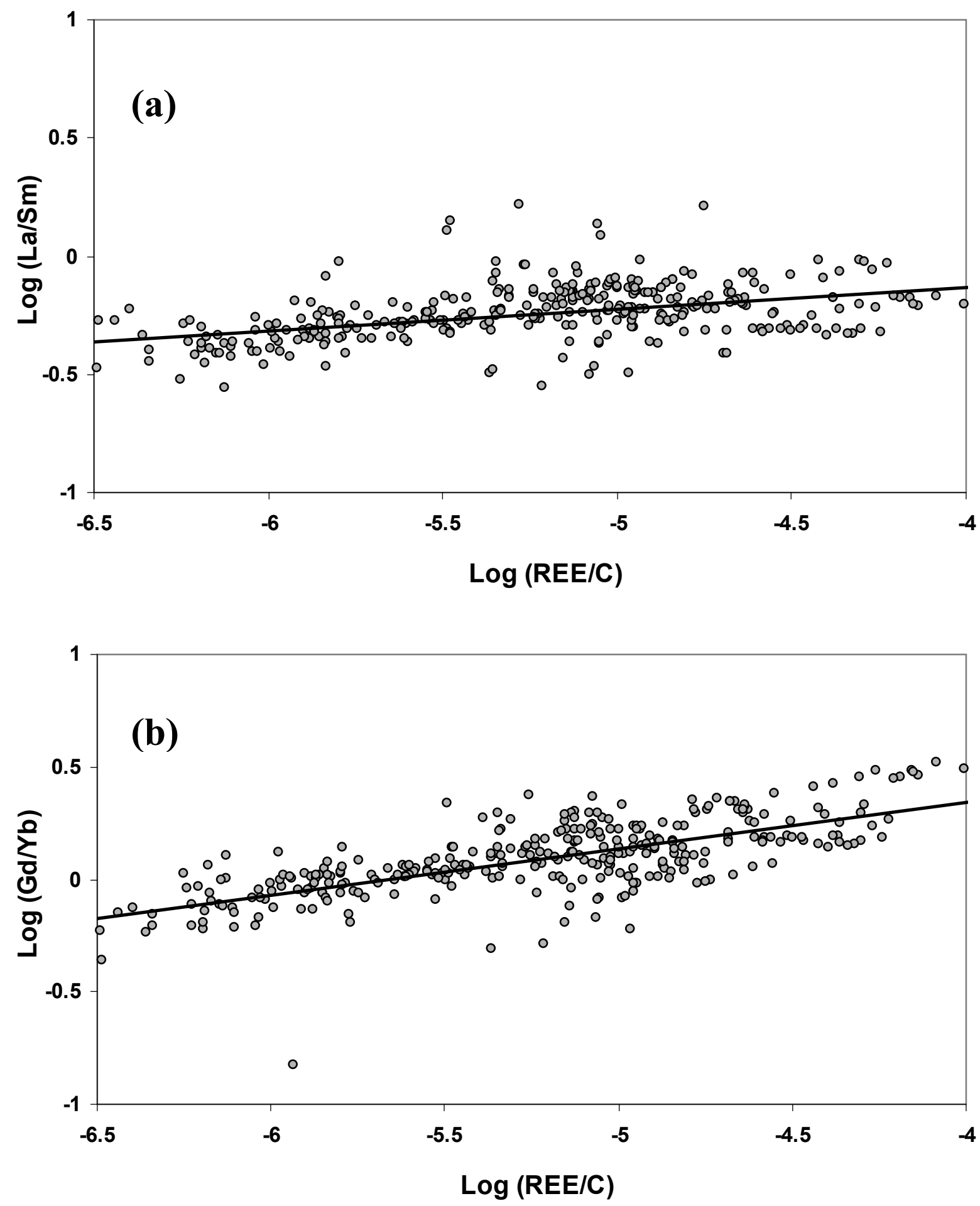

Figure 9 